\title{
Metabolomics differentiation of oil palm (Elaeis guineensis Jacq.) spear leaf with contrasting susceptibility to Ganoderma boninense
}

\author{
Nurul Liyana Rozali ${ }^{1}$, Mohd Ambar Yarmo ${ }^{2}$, Abu Seman Idris ${ }^{1}$, Ahmad Kushairi ${ }^{1}$, Umi Salamah \\ Ramli $^{\mathbf{1}^{*}}$
}

\author{
${ }^{1}$ Malaysian Palm Oil Board, No. 6, Persiaran Institusi, Bandar Baru Bangi, 43000 Kajang, Selangor, Malaysia \\ ${ }^{2}$ School of Chemical Sciences and Food Technology, Faculty of Science and Technology, Universiti Kebangsaan \\ Malaysia, 43600 Bangi, Selangor, Malaysia
}

*Corresponding author: umi@mpob.gov.my

\begin{abstract}
Basal stem rot (BSR) disease caused by Ganoderma boninense is the most serious and destructive disease in oil palm, especially in Southeast Asia and required urgent control measures to combat the disease outbreak. Information of understanding metabolite response of oil palm to BSR is limited. Therefore, parental palms with contrasting susceptibility to G. boninense based on previous oil palm progenies testing using root inoculation technique to identify oil palm progenies partially tolerant and susceptible to $G$. boninense were examined by metabolomics approach using gas chromatography $\mathrm{x}$ gas chromatography-time-of-flight mass spectrometry (GC $\times \mathrm{GC}-\mathrm{TOF}-\mathrm{MS})$. Analysis of metabolomics data from GC $\times \mathrm{GC}-\mathrm{TOF}-\mathrm{MS}$ was conducted by supervised multivariate analysis of partial least squares-discriminant analysis (PLS) and orthogonal partial least squares-discriminant analysis (OPLS-DA) that allowed cross-validation and response permutation test functions. As a result, seven potential metabolites that contribute to the contrasting susceptibility of oil palms to $G$. boninense were identified as mannose, xylose, glucopyranose, myo-inositol and hexadecanoic acid which were found high in partially tolerant oil palm whereas cadaverine and turanose were found high in susceptible oil palm as observed in fold changes of detected GC $\times$ GC-TOF-MS peaks. The results suggest that the employed strategy is a potential approach to profile and characterize leaf metabolome with contrasting susceptibility to G. boninense. This result provide baseline in future studies utilizing metabolomics in identifying potential biomarkers by screening larger population of truly resistant palms to $G$. boninense.
\end{abstract}

Keywords: Basal stem rot; Ganoderma boninense; GC×GC-TOF-MS; Metabolomics; Multivariate analysis; Oil palm (Elaeis guineensis) spear leaf.

Abbreviations: BSR_Basal stem rot; CV-ANOVA_Cross-validated analysis of variance; G. boninense Ganoderma boninense; GC $\times$ GC-TOF-MS_ Gas chromatography $x$ gas chromatography-time-of-flight mass spectrometry; MSTFA_ N-methyl-N(trimethylsilyl)trifluoroacetamide; NIST_ National Institute of Standards and Technology; OPLS-DA_Orthogonal partial least squares-discriminant analysis; PLS-DA_Partial least squares-discriminant analysis; VIP_Variable importance for projection.

\section{Introduction}

Oil palm (Elaeis guineensis Jacq.) is the world's highest yielding edible oil crop as it produced 60.9 million tonnes of palm oil and 6.67 million tonnes of palm kernel oil, which roughly account for $29.4 \%$ of the world production of oils and fats in year 2016 (Oil World Annual, 2016). Palm oil is mainly used as an edible product in a wide range of dietary components and non-food sector (Sundram et al., 2003). Malaysia is currently the second largest producer and also one of the biggest exporters of palm oil in the world. As for today, 5.74 million hectares of oil palm plantation in Malaysia producing 17.32 million tonnes crude palm oil (CPO) with export revenue of oil palm in 2016 reached RM64.58 billion (MPOB, 2016). However, the oil palm industry is facing several challenges including lack of suitable land, shortage of labour and the oil palm diseases. Among the oil palm diseases that occur in oil palm plantations, basal stem rot (BSR) caused by $G$. boninense is the most destructive (Susanto et al., 2005). In Malaysia, BSR has caused severe losses of overall yield per hectare with increasing incidence and for which more effort and action have to be taken to overcome the problem. BSR can cause economic losses between RM225 million to RM1.5 billion a year (Hushiarian et al., 2013). Once the disease has affected more than $10 \%$ of the stand, economic loss will begin (Hasan and Turner, 1998) and further loss of the stand to $50 \%$ will cause a $35 \%$ reduction in fresh fruit bunch (FFB) yield (Cooper et al., 2011). There were control measures being adopted by plantation management to minimize the spread of BSR which include soil mounding, sanitation by removal of diseased palm, stump treatment with dazomet, fungicide hexaconazole, biological treatment and recently development of GanoCareTM fertilizer (Idris et al., 2015; Idris, 2011). These treatments can only control the disease and at best only slow down the disease progress. The availability of tolerant palm to $G$. boninense is one of the most important priorities in terms of increasing the overall output of the oil palm industry. Possible sources of highly resistance palm to BSR have been reported through progeny testing to $G$. boninense (Durand-Gasselin et al., 2005; Idris et al., 2004). G. boninense study on root inoculation technique provide 
important information towards understanding BSR mechanism as well as looking into molecular diagnostic tool for early disease detection including protein and metabolite markers (Syahanim et al., 2013). Metabolomics analysis can help uncover details of mechanism in disease tolerance at molecular level. Plant metabolites in oil palm roots which are lipids and heterocyclic aromatic organic metabolites might response in early defence mechanism towards $G$. boninense infection (Nusaibah et al., 2016). In other studies, LC-MS approach has been used to profile metabolite in the partially tolerant and susceptible oil palm suggesting phenolics metabolite might be significant for distinguish these palms with contrasting susceptibility to $G$. boninense (Nurazah et al., 2013). Metabolomics tool has been widely used in application of plant disease and helps to understand the metabolites that may functionality contribute to plant susceptibility and resistance to pathogens (Allwood et al., 2008) in which gas chromatography-mass spectrometry (GCMS) is one of the technique used in application of metabolite profiling. This tool have been successfully applied to study metabolite changes in rice leaf subjected to fungal pathogen Magnaporthe grisea and the results obtained suggested that metabolomics has potential to unravel metabolites in distinguished different susceptibility of rice leaf with response in plant-pathogen interactions (Jones et al., 2011). Besides that, there was also investigation of volatile metabolite content changes in healthy and inoculated tomato with three different bacterial pathogens to provide information of pathogens involvement during postharvest handling, storage and the food borne disease of tomato (Ibrahim et al., 2011). The data obtained from the analytical tool was usually first subjected to chemometrics analysis for data analysis. Partial least squares-discriminant analysis (PLS-DA) and orthogonal partial least squares-discriminant analysis (OPLS-DA) is one of the supervised chemometric tools widely used in metabolomics in which supervised chemometric method provides a way of troubleshooting potential metabolites responsible for variation within the groups of samples analysed (Seger and Sturm, 2007).

To date, no known comprehensive study on oil palm spear leaf has been analysed with GC-MS and multivariate analysis towards understanding mechanism involved in oil palm-G. boninense interaction and metabolite biomarkers or phenotyping associated to BSR in oil palm. The use of GCxGC-TOF-MS and multivariate analysis are enabling potential metabolites involved in disease mechanism and to distinguish the oil palm with contrasting in susceptibility to $G$. boninense at the level of metabolites in their leaf extracts. In the future, it will be desirable for oil palm researchers to analyse a wider range of broadly applicable metabolomics tools for the identification of metabolites from highly or true resistant palm to $G$. boninense and to improve the credence of potential metabolites towards biomarkers discovery. This will be enable breeders to use the marker in a relatively reliable way of screening large population for the tolerant palm to G. boninense.

\section{Results and Discussion}

\section{Multivariate analysis of oil palm spear leaf partially tolerant and susceptible to G. boninense}

The data from GCxGC-TOF-MS were analysed by the SIMCA-P+ software to comprehensively distinguish between the spear leaf metabolomes of partially tolerant and susceptible oil palms. The data were first loaded into the unsupervised principle component analysis (PCA) to obtain trend of separation of samples according to groups. However, no clear separation was obtained to differentiate the two groups of the oil palms, therefore, further separation of the groups were performed by supervised analysis of partial least squares-discriminant analysis (PLS-DA) and orthogonal partial least squares-discriminant analysis (OPLS-DA) model. PLS-DA regression, also known as projection on latent structures is a method practically used for classification a set of group samples and selection of biomarker in metabolomics studies (Szymańska et al., 2012). The model is built between dependent variables $(\mathrm{Y})$ and independent variables (X) (i.e. predictors) simultaneously, where the dependant variables $(Y)$ represent samples classification (e.g. two groups of samples were set as A and B) and mapped into a linear space, therefore PLS-DA can improved the separation between two groups of samples. In this analysis, the dependent variables (Y) were set as (1) susceptible oil palms, (2) as partially tolerant oil palms. The aim of the PLSDA model is to predict a set of dependent variables (Y) from a set of independent variable $(\mathrm{X})$ to find the latent variables (LVs) which have the best predictive power. The LVs are aligned along the direction that maximizes the covariance between $\mathrm{X}$ and $\mathrm{Y}$ variables (Robotti et al., 2014). In this analysis, the separation of the two groups of the oil palms in the PLS-DA model were explained by the first two LVs (LV1 versus LV2) of the total spectral variation, which accounted for $62.5 \%$ (Fig. 1). The same data were further analysed with OPLS-DA model which is also known as orthogonal projections to latent structures, an extension of PLS regression method presenting an integrated orthogonal signal correction filter which separates the systematic variation in $\mathrm{X}$ into two parts, one that is linearly related to $\mathrm{Y}$ and one that is orthogonal to Y. Hence, the OPLS model consists of two blocks of modeled variation which are the Ypredictive block refer to variation between the class and $\mathrm{Y}$ orthogonal block represents uncorrelated variation within the class (Wiklund et al., 2008; Bylesjö et al., 2007). OPLS-DA model data in this analysis resulted in usage of one predictive and three orthogonal component $(1+2)$ and clear separation of a metabolic signature between partially tolerant and susceptible palm were observed in OPLS-DA score plot (Fig. 2). Both PLS-DA and OPLS-DA models qualities were cross validated with $\mathrm{R}^{2}$ and $\mathrm{Q}^{2}$ (goodness of fit) parameters. In this study, the PLS-DA model gave the values of $R^{2} X$ (cum) of $0.727, \mathrm{R}^{2} \mathrm{Y}$ (cum) of 0.867 and $\mathrm{Q}^{2}$ (cum) of 0.701 while OPLS-DA model had the $R^{2} \mathrm{X}$ (cum) of $0.727, \mathrm{R}^{2} \mathrm{Y}$ (cum) of 0.867 and $Q^{2}$ (cum) of 0.796 (Table 1). Values of $R^{2}$ and $Q^{2}$ near to 1.0 indicate perfect description and perfect predictability of the model respectively (Triba et al., 2015). In general, values of $\mathrm{R}^{2}$ and $\mathrm{Q}^{2}$ more than $50 \%$ are considered satisfactory for metabolic experiment and are able to explain the model (Azizan et al., 2015). Hence, the models can be utilized to explain the discrimination between partially tolerant and susceptible oil palms. The model was further validated using CV-ANOVA and permutations test (Xu et al., 2015). The CV-ANOVA is constructed on cross validation for the estimation of independent predictors (OPLS-scores) and predictive residuals. The use of $\mathrm{CV}$ predictive residuals makes the CV-ANOVA more consistent than ordinary ANOVA. Lower $p$-value showed that the group separation was high (Musharraf et al., 2016). Here in this analysis the $p$-value for the model was $p=0.000110969$ suggesting that the group separation was significant. The values of $\mathrm{R}^{2}$ intercept (goodness of fit) and $\mathrm{Q}^{2}$ intercept (predictive capability) in permutation test should be $<0.4$ and $<-0.04$, respectively (Ma et al., 2009) and this model had $\mathrm{R}^{2}$ intercept of 0.354 and $\mathrm{Q}^{2}$ intercept of -0.429. Furthermore, 
Table 1. Explanation and predictability values of the partial least squares-discriminant analysis (PLS-DA) and orthogonal partial least-squares-discriminant analysis (OPLS-DA) of partially tolerant and susceptible oil palms.

\begin{tabular}{lccc}
\hline & $\mathrm{R}^{2} \mathrm{X}$ & $\mathrm{R}^{2} \mathrm{Y}$ & $\mathrm{Q}^{2}$ \\
\hline PLS-DA & 0.727 & 0.867 & 0.701 \\
OPLS-DA & 0.727 & 0.867 & 0.796 \\
\hline
\end{tabular}

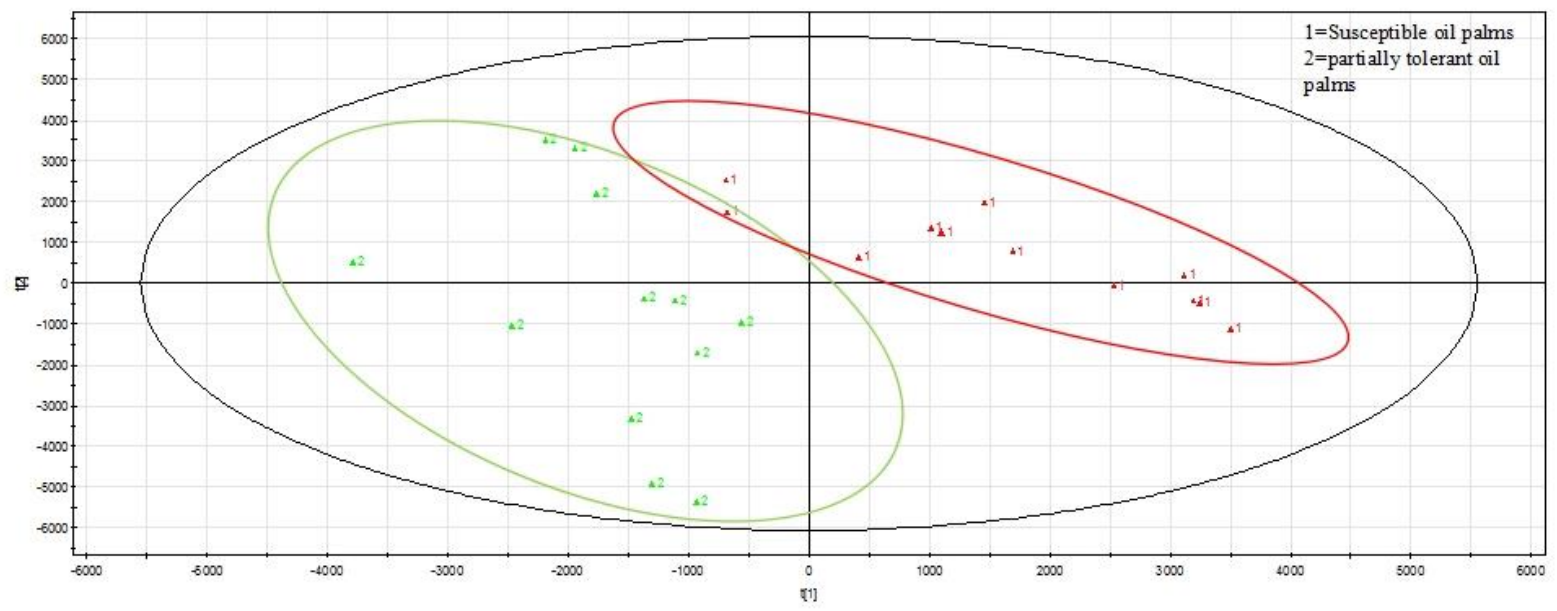

Fig 1. PLS-DA score plot based on GCxGC-MS-TOF data of partially tolerant and susceptible oil palms that was performed using LV1 vs LV2 and gave a total variance of $62.5 \%$.

Table 2. Seven metabolites that contribute to the grouping of partially tolerant and susceptible oil palm with VIP $>1$ and $p<0.05$.

\begin{tabular}{|c|c|c|c|c|c|}
\hline No & Metabolites & RT (sec) & $\log _{2}(\mathrm{FC})$ & $p$-value & CAS \\
\hline 1 & $\begin{array}{l}\text { Mannose (MEOX- } \\
\text { 5TMS) }\end{array}$ & 1619 & 0.96 & 0.037 & $128705-67-9$ \\
\hline 2 & $\begin{array}{l}\text { Xylose } \\
\text { (MEOX-4TMS) }\end{array}$ & 1599 & 1.11 & 0.026 & $18623-22-8$ \\
\hline 3 & $\begin{array}{l}\text { Glucopyranose } \\
\text { (5TMS) }\end{array}$ & 1646 & 1.25 & 0.028 & - \\
\hline 4 & $\begin{array}{l}\text { Hexadecanoic acid } \\
\text { (TMS) }\end{array}$ & 1682 & 0.51 & 0.002 & $55520-89-3$ \\
\hline 5 & Myo-inositol (6TMS) & 1736 & 0.48 & 0.002 & $2582-79-8$ \\
\hline 6 & $\begin{array}{l}\text { Cadaverine } \\
\text { (4TMS) }\end{array}$ & 1613 & -1.11 & 0.001 & $65898-76-2$ \\
\hline 7 & Turanose (7TMS) & 2370 & -0.97 & 0.002 & $60065-05-6$ \\
\hline
\end{tabular}

RT (sec); retention time in seconds, $\log _{2} \mathrm{FC}$; $\log _{2} \mathrm{FC}$ (partially tolerant/susceptible oil palms).

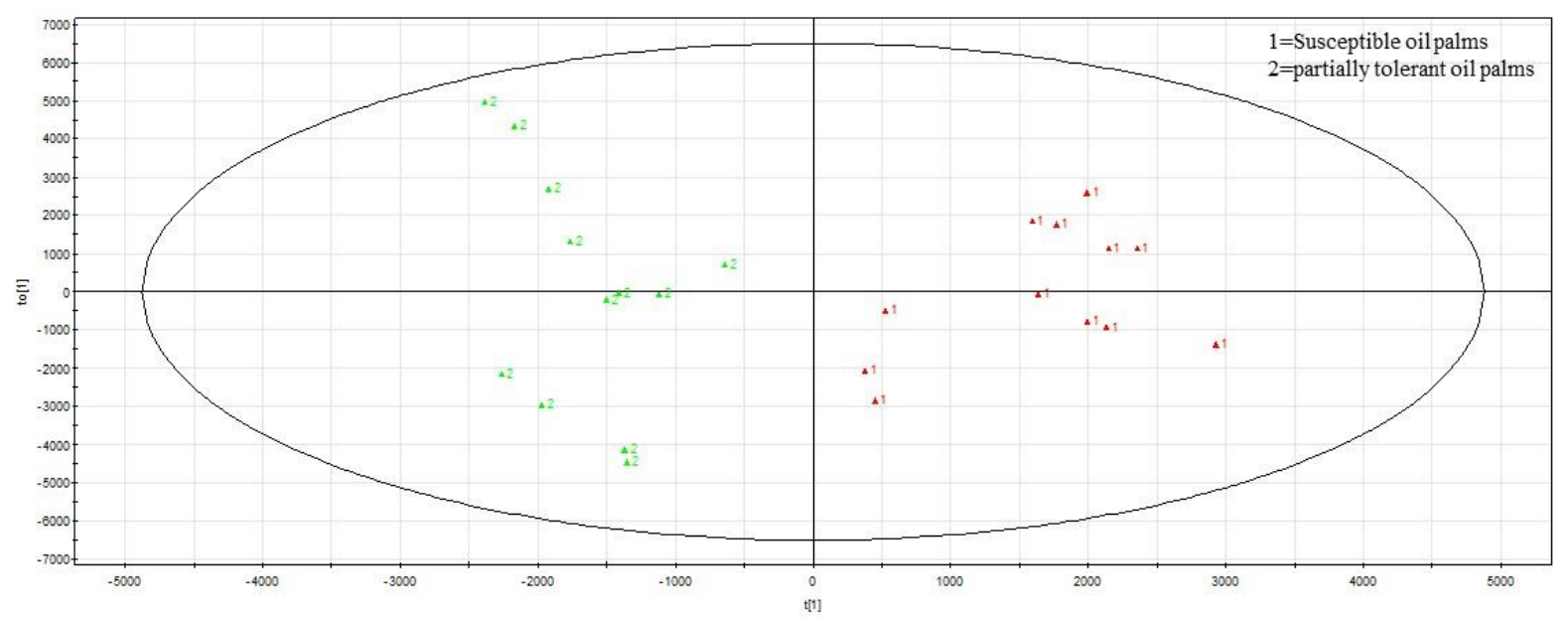

Fig 2. OPLS-DA score plot of partially tolerant and susceptible oil palms with values of $R^{2} X=0.727, R^{2} Y=0.867$ and $Q^{2}=0.796$. 


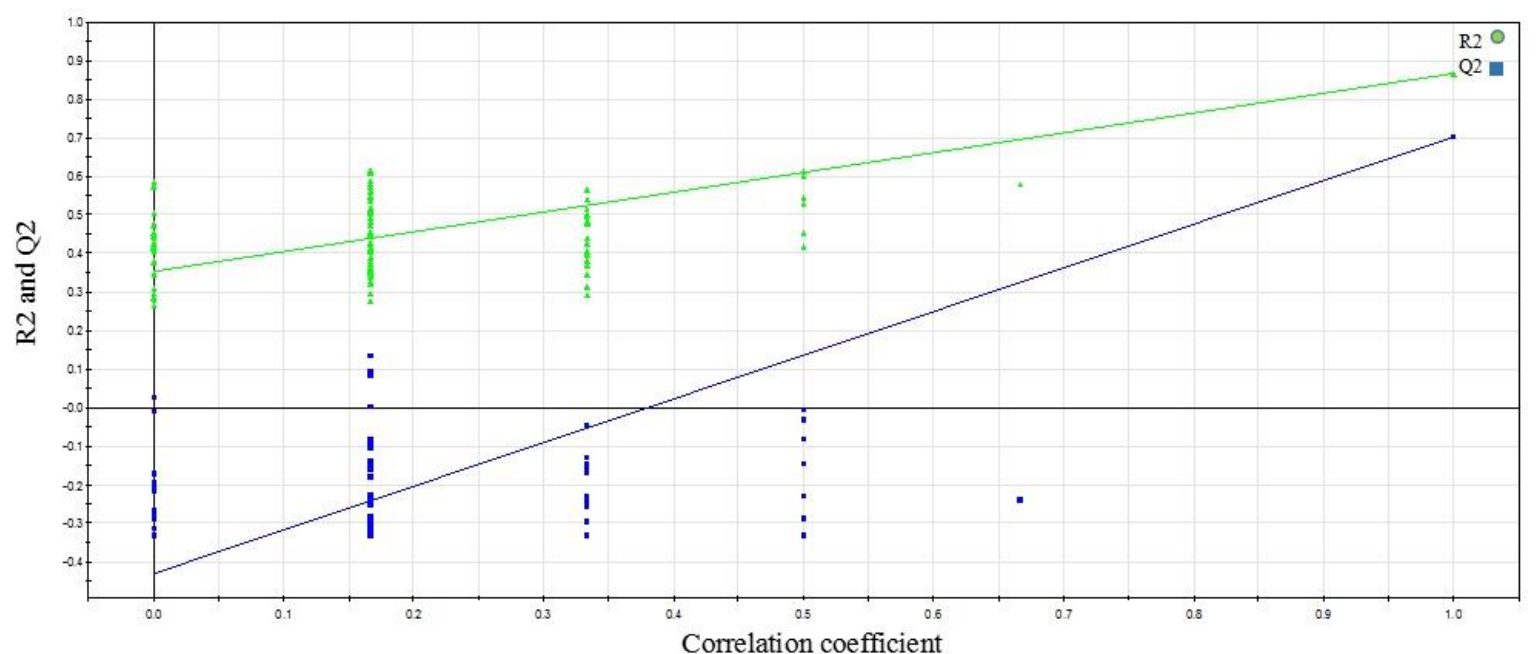

Fig 3. Response permutation test $(n=100)$ derived from PLS-DA model. Actual model parameter is on the right-hand side while the permutated model parameter is on the left-hand side. The actual model parameter exhibited higher values that permutated model parameters with value of R2 and Q2, 0.354 and -0.429 respectively.

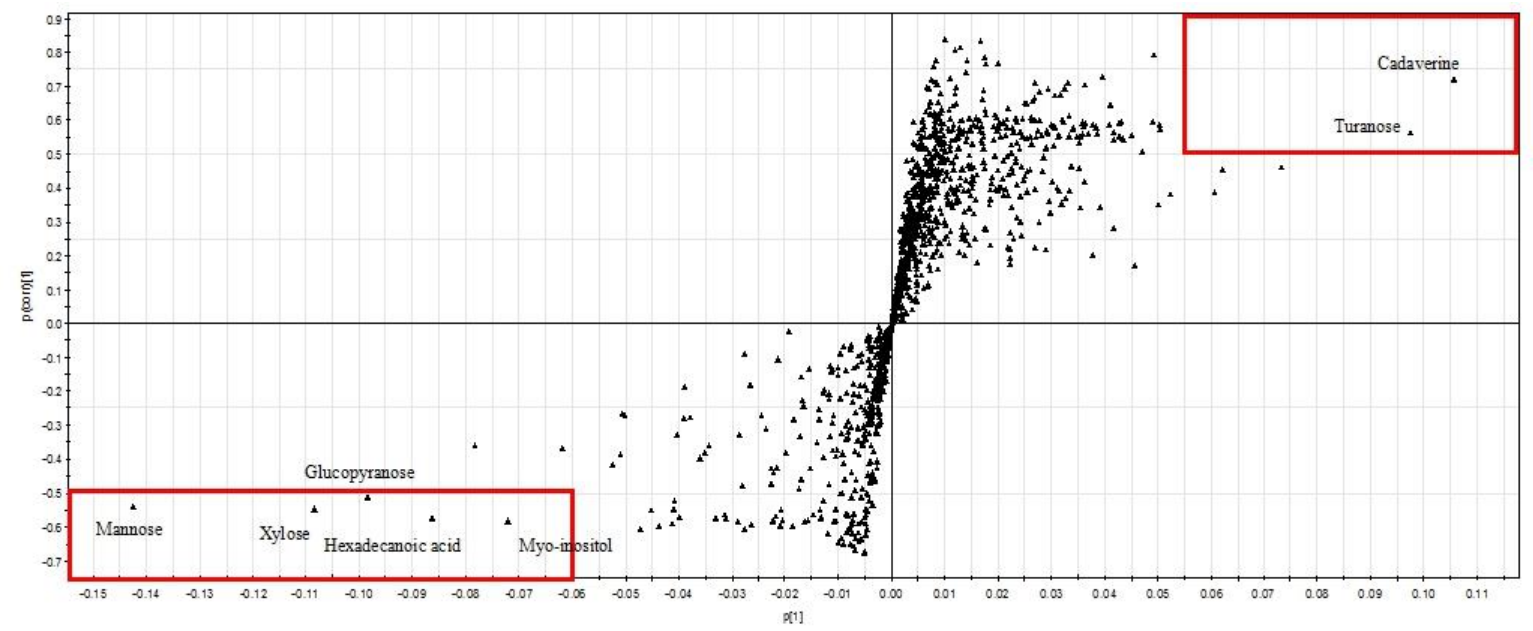

Fig 4. S-plot derived from OPLS-DA for partially tolerant and susceptible oil palms with value of $p \geq|0.05|$ and $\mathrm{p}$ (corr) $\geq|0.5|$, which showed the significant different metabolites for each group (in box).

the original model was on far right and remained higher than those of the 100 permuted models to the left (Fig. 3). Therefore, the result displayed good elucidation of the sample classification information and can be further analysed. By using OPLS-DA, an improved visualization and discrimination of the metabolites between the two groups of oil palms could be exhibited. To find out metabolites that have most significant influence the groups of partially tolerant and susceptible oil palms for the discrimination, Splot derived from OPLS-DA was acquired. S-plot was created using the loading profile of the first component $(\mathrm{p})$ and correlation of the first component ( $\mathrm{p}$ (corr.)) to visualize both the covariance and correlation between the metabolites and the groups of classification. Metabolites responsible for the class classification were selected with $p \geq|0.05|$ (magnitude) and $p$ (corr.) $\geq|0.5|$ (reliability) from the S-plot which indicate the metabolites distinguishing the two groups (Kim et al., 2015; Suvagandha et al., 2014) and values of variable importance for projection (VIP) which were exceeding 1.0 were set as metabolite cut-off. From the observation of S-plot, seven (7) metabolites were found to contribute to the grouping of partially tolerant and susceptible oil palms. All the seven (7) metabolites had the VIP values more than 1.0 and they were individually identified by comparing the detected mass-to-charge $(\mathrm{m} / \mathrm{z})$ ratios against a standard mass chromatogram from National Institute of Standards and Technologies (NIST) database with peaks similarity and reverse number more than 800 (Dallüge et al., 2003). Five (5) metabolites which were found high in partially tolerant oil palms were mannose $\left(\mathrm{C}_{6} \mathrm{H}_{12} \mathrm{O}_{6}\right)$, xylose $\left(\mathrm{C}_{5} \mathrm{H}_{10} \mathrm{O}_{5}\right)$, glucopyranose $\left(\mathrm{C}_{6} \mathrm{H}_{12} \mathrm{O}_{6}\right)$, myo-inositol $\left(\mathrm{C}_{6} \mathrm{H}_{12} \mathrm{O}_{6}\right)$ and hexadecanoic acid $\left(\mathrm{C}_{16} \mathrm{H}_{32} \mathrm{O}_{2}\right)$ (lower left-side box in Fig. 4) with positive values of fold change indicating higher presence in partially tolerant oil palm. Two metabolites were found high in susceptible palms (upper right-side box in Fig. 4) were identified as cadaverine $\left(\mathrm{C}_{5} \mathrm{H}_{14} \mathrm{~N}_{2}\right)$ and turanose $\left(\mathrm{C}_{12} \mathrm{H}_{22} \mathrm{O}_{11}\right)$ with negative values of fold change indicating higher presence in susceptible oil palms. All the seven (7) metabolites showed the $p$-value < 0.05 (Table 2).

\section{Seven metabolites contributing to the grouping of partially tolerant and susceptible oil palms in S-plot of OPLS-DA}

According to S-plot derived form OPLS-DA model, five metabolites which were mannose, xylose, glucopyranose, myo-innositol and hexadecanoic acid were found high in spear leaf of partially tolerant palms. These metabolites are 
vital for plant growth and defence mechanism against pathogen. Mannose and xylose are monomers of hemicellulose. Basically, hemicellulose is a polysaccharides and is one of the components of the cell wall besides cellulose and pectin (Scheller and Ulvskov, 2010). The physiology of plant cell wall polysaccharides with high structural complexity has suggested the possibility of a response and release components that might lead to defence mechanism by the plant (Vorwerk et al., 2004). Generally, most plant pathogens actively penetrate the plant cell barrier to access intracellular nutrients and successively, to strengthen the cell wall, plants release antimicrobial compounds into the cell wall to stop pathogen penetration. Different composition of cell wall components affects defensive response against pathogens in Arabidopsis thaliana (Ramirez et al., 2011). Thus, high deposition of polysaccharides (to strengthen the cell boundary) is required as an effective line defence for the plant. Significantly higher level of xylose was detected in rice leaf cell walls of GIF1$\mathrm{OE}$ in which GIF1-OE was found more resistant than wildtype against pathogens Xanthomonas oryzae pv. Oryzae and Magnaporthe oryzae (Sun et al., 2014). In addition, higher level of xylose were reported to contribute to thicker cell wall and enhanced resistance against pathogen in Arabidopsis thaliana and proved to be a defence mechanism against corn borer (Ostrinia nubilalis) in resistant inbred lines of maize (Zea mays) (Miedes et al., 2014; Barros-Rios et al., 2011). Therefore, high level of xylose metabolite in partially tolerant palms might contribute to high accumulation of plant cell wall in oil palm tissues that can be related to high resistance of the oil palms.

Increase in abundance of glucopyranose and myo-inositol metabolites in resistant wheat cultivar to Fusarium head blight (FHB) were managed to be observed in GC-MS analysis (Hamzehzarghani et al., 2005). Myo-inositol is one of the stereoisomers of inositol which is widely occurring in nature. It is a compound that is used for development and growth process in plant. Over expression of inositol were reported in resistant plants to diseases (Smart and Flores, 1997).

The hexadecanoic acid, a compound of a fatty acid group, was also detected in high presence in partially tolerant oil palms. Several fatty acids have been documented to have antimicrobial activity (Walters et al., 2004). In plant pathway elucidation, hexadecanoic acid is required for the synthesis of jasmonic acid which can be via at least two pathways, the established octadecanoid pathway from linolenic acid (C18:3) and the hexadecanoid pathway from hexadecatrienoic acid (C16:3) (Farmer et al., 1998). Jasmonic acid functions as a trigger to the phenylpropanoid pathway to increase the synthesis of phenolic compounds (Gundlach et al., 1992). Hexadecanoid acid plays as significant role in the synthesis of jasmonic acid and can stimulate the resistance mechanism in plants. Metabolomics analysis using GC-MS discovered hexadecanoic acid and myo-inositol as the resistance related constitutive metabolites by which resistance-related (RR) metabolite is defined as metabolites that are in higher abundance in wheat resistant near isogenic lines (NIL) than susceptible wheat NIL to FHB (Hamzehzarghani et al., 2008). Recently, high level of hexadecanoic acid was also detected in resistant root samples of oil palm which was proven to play a role in defense mechanisms (Nusaibah et al., 2016).

Another two metabolites which were turanose and cadaverine were found high in susceptible palm. Cadaverine is a metabolite from amine group. To our best knowledge, reports on plant defence mechanism involving cadaverine and turanose are still inadequate. In rice treatment with rhizobacteria Bacillus amyloliquefaciens (SN13) against pathogenic Rhizoctonia solani, turanose among other metabolites were catabolized to maintain survival of the plant (Srivastava et al., 2016). Cadaverine was also being detected high in inoculated susceptible cultivar of soybean germplasm to Fusarium tucumaniae, the main causes of sudden death syndrome (SDS) of soybean in Argentina (Scandiani et al., 2015). These results deserve further validation with a large number of susceptible and tolerant oil palm to provide more assurance that the screening method can predict cultivar response to $G$. boninense infection in the field.

\section{Materials and Methods}

\section{Chemicals and reagents}

Internal standards (ribitol, $\mathrm{C}_{5} \mathrm{H}_{12} \mathrm{O}_{5}$ ) and dried pyridine were purchased from Sigma-Aldrich (Steinheim Germany), and methanol LichroSolv and chloroform SupraSolv (HPLC grade) are from Merck (Darmstadt, Germany). Omethoxyamine hydrochloride (98\%) was obtained from Fluka (Germany) and N-methyl-N-(trimethylsilyl) trifluoroacetamide (MSTFA) is from Thermo Scientific (Rockford, USA).

\section{Plant materials}

Spear leaf from six biological replicates of partially tolerant parental palms and six susceptible parental palms were selected based on the diagram (Nurazah et al., 2013) translated from a study conducted by Idris et al. (2004) on selection of oil palm progenies for resistance to G. boninense. They were collected in Malaysian Palm Oil Board (MPOB) Kluang Research Station, Johor, Malaysia. The samples were harvested from 8.30 to $10.30 \mathrm{am}$, immediately washed with water to remove any dust and cut into $2-3 \mathrm{~cm}$ pieces. Then the fresh pieces were immediately frozen in liquid nitrogen in order to quench enzyme activity and kept at $-80^{\circ} \mathrm{C}$ for further analyses.

\section{Extraction and derivatization of oil palm spear leaf metabolites}

Method of extraction was adapted from Morgenthal et al. (2007) with slight modification. Spear leaves were ground to a fine powder. Approximately $0.100 \mathrm{~g}$ of the spear leaf powder was weighed and added with $1.4 \mathrm{ml}$ methanol and 60 $\mu 1000 \mathrm{ppm}$ ribitol as an internal standard. The samples were centrifuged at $4000 \mathrm{rpm}$ for $30 \mathrm{~min}$. Eight hundred microlitres of chloroform and $1 \mathrm{ml}$ water was added to the liquid phase. The extracts were again centrifuged at $4000 \mathrm{rpm}$ for $30 \mathrm{~min}$ and the resulting upper layer was collected. The lower phase was re-extracted in $1 \mathrm{ml}$ methanol followed by centrifugation at $4000 \mathrm{rpm}$ for $30 \mathrm{~min}$. Next the supernatant was dried under nitrogen stream. Then, the resulting pellet was dissolved in $20 \mu 1$ methoxymine hydrochloride in dried pyridine solvents $(20 \mathrm{mg} / \mathrm{ml})$ and incubated at $37^{\circ} \mathrm{C}$ for 90 min with rigorous shaking. Next, $180 \mu \mathrm{l}$ N-methyl-N(trimethylsilyl)trifluoroacetamide (MSTFA) was added and the samples were incubated at $37^{\circ} \mathrm{C}$ for another $30 \mathrm{~min}$ followed by rigorous shaking. The ratio used for methoxymine hydrochloride in dried pyridine solvents: MSTFA is 1:9 where lower amounts of pyridine will give better peak shapes with spitless injection (Fiehn, 2006). 


\section{GC $\times G C-T O F-M S$ experimental conditions}

The samples were analyzed with a LECO Pegasus 4D GC $\times$ GC-TOF-MS (LECO Corporation, St. Joseph, MI, USA) equipped with an Agilent 6890 N GC. The first column was $30 \mathrm{~m} \times 250 \mu \mathrm{m} \times 0.25 \mu \mathrm{m}, \mathrm{Rtx}-5$ with $10 \mathrm{~m}$ integrated guard column (Restek Corporation, Bellefonte, USA) and the second column was $1 \mathrm{~m} \times 0.10 \mathrm{~mm} \times 0.10 \mu \mathrm{m}$ Rxi-17 (Restek Corporation, Bellefonte, USA). Cryogenic modulation was used for $5 \mathrm{sec}$. High purity helium (99.99\%) was the carrier gas and was set at a constant flow of 1.0 $\mathrm{ml} / \mathrm{min}$. The first column oven was held at $50^{\circ} \mathrm{C}$ for $5 \mathrm{~min}$ and then ramped at $10^{\circ} \mathrm{C} / \mathrm{min}$ up to $265^{\circ} \mathrm{C}$ for $20 \mathrm{~min}$ while the second column oven was held at constant $15^{\circ} \mathrm{C}$ higher than the first column oven. The GC inlet and transfer line were set at $250^{\circ} \mathrm{C}$ and $280^{\circ} \mathrm{C}$, respectively. The ion source was set at $200^{\circ} \mathrm{C}$ and the solvent delay time was $15 \mathrm{~min}$. Mass spectra from $\mathrm{m} / \mathrm{z} 45-1000$ were collected at 20 spectra per second. The detector voltage was $1600 \mathrm{~V}$ and electron energy was $70 \mathrm{eV}$.

\section{Data processing}

The raw data were processed with LECO ${ }^{\circledR}$ ChromaTOF® optimized for Pegasus ${ }^{\circledR}$ 4D software. The data acquired from the workstation were converted to cumulative distribution function (.cdf) and were imported into the XCMS software (http://metlin.scripps.edu/xcms/) which is based on the $\mathrm{R}$ software platform (www.r-project.org). Internal standard and the masses of $m / z 73,147$ and 207 peaks caused by column bleed (from the stationary phase) and MSTFA derivatization procedure were omitted (Wang et al., 2015; Hill and Roessner, 2013). Finally, the data set in excel format contained samples information, retention times and peak areas were further analyse with multivariate analysis.

\section{Multivariate analysis of PLS-DA and OPLS-DA}

PLS-DA and OPLS-DA supervised analysis were performed with software SIMCA-P+ Version 12.0 (Umetrics AB, Sweeden). Both analysis models were applied to the data with Pareto scaling to enhance slow abundant peaks without significant amplification of noise (Wang et al., 2013). The $\mathrm{R}^{2}$ (cum) and $\mathrm{Q}^{2}$ (cum) values were extracted to explain the models for its goodness of prediction, representing total explained variance and the model predictability. CVANOVA and permutation methods were also employed on the models for their further validness. To identify the metabolites that significantly contribute to the variation of the groups, the values of variable importance in projection (VIP) were inspected. In the SIMCA-P+ software, the VIP value is unitless and was created based on a weighted and quantitative measure of discriminatory power of the metabolites. The greater the VIP number represent the higher discriminatory power of the metabolite and VIP scores $>1$ generally show the metabolites that carrying highly discriminating information between the classes (Davis et al., 2012).

\section{Conclusion}

The development of rapid and robust metabolomics method such as GC-MS to screen out potential metabolite markers is a novel strategy that will improve the understanding on the oil palm defence mechanisms against $G$. boninense. Although resistant materials are not readily available, a batch of leaf tissue samples analysed by multivariate statistical analysis could be representatives in distinguishing the partially tolerant from susceptible oil palms. Several metabolite markers from different classes of plant compounds were identified, which have potential as defence-related oil palm metabolites markers for basal stem rot (BSR). However, the elucidation of these metabolites involvement in the tolerance mechanism against $G$. boninense remains to be deciphered. The developed method may be applied for future selective breeding of oil palm plants (metabolomics-assisted breeding technique).

\section{Acknowledgements}

The authors would like to thank the Director General of MPOB for permission to publish this paper. We thank Dr Mohd Din Amiruddin, Mr Marhalil Marjuni from Breeding and Quantitative Genetics Group, Malaysian Palm Oil Board (MPOB) for the spear leaf samples used in this study and Ms Norzamzurina Ismail, Centre for Research and Instrumentation (CRIM) for the technical assistance during GC-MS analysis. This research was funded by Board approved programme (R00560600) and MPOB-Graduate Students Assistantship Scheme (GSAS) scholarship.

\section{References}

Allwood JW, Ellis DI, Goodacre R (2008) Metabolomics technologies and their application to study of plants and plant-host interactions. Physiol Plant. 132:117-135.

Azizan KA, Ghani NHA, Nawawi MF (2015) GC-MS based metabolomics and multivariate

statistical analysis of Wedelia trilobata extracts for the identification of potential phytochemical properties. Plant Omics. 8(6):537-543.

Barros-Rios J, Malvar RA, Jung H-JG, Santiago R (2011) Cell wall composition as a maize defense mechanism against corn borers. Phytochem. 72:365-371.

Bylesjö M, Rantalainen M, Cloarec O, Nicholson JK, Holmes E, Trygg J (2007) OPLS discriminant analysis: combining the strengths of PLS-DA and SIMCA classification. J Chemometr. 20:341-351.

Cooper RM, Flood J, Rees RW (2011) Ganoderma boninense in oil palm plantations: current thinking on epidemiology, resistance and pathology. The Planter. 87(1024):515-526.

Dallüge J, Beens J, Brinkman UA (2003) Comprehensive two-dimensional gas chromatography: a powerful and versatile analytical tools. J Chromatogr A. 1000(1-2):69108

Davis VW, Schiller DE, Eurich D, Sawyer MB (2012) Urinary metabolomic signature of esophageal cancer and Barrett's esophagus. World J Surgical Oncology. 10:1-12.

Durand-Gasselin T, Asmandy H, Flori A, Jacquemard JC, Hayun Z, Breton F, de Franqueville H (2005) Possible sources of genetic resistance in oil palm (Elaeis guineensisJacq.) to basal stem rot caused by Ganoderma boninense - prospects for future breeding. Mycopathologia. 159:93-100.

Farmer EE, Weber H, Vollenweider S (1998) Fatty acid signalling in Arabidopsis. Planta. 206:167-174.

Fiehn O (2006) Metabolite profiling in Arabidopsis. In: Salinas J, Sanchez-Serrano JJ (ed) Arabidopsis Protocols, Methods Mol Biol, vol. 323, 2nd edn. Humana Press, Totowa, New York.

Gundlach H, Müller MJ, Kutchan TM, Zenk MH (1992) Jasmonic acid is a signal transducer in elicitor-induced plant cell cultures. Proc Natl Acad Sci USA. 89:2389-2393. 
Hamzehzarghani H, Kushalappa AC, Dion Y, Rioux S, Comeau A, Yaylayan V, Marshall WD, Mather DE (2005) Metabolic profiling and factor analysis to discriminate quantitative resistance in wheat cultivars against Fusarium head blight. Physiol Mol Plant P. 66:119-133.

Hamzehzarghani H, Paranidharan V, Abu-Nada Y, Kushalappa AC, Mamer O, Somers D (2008) Metabolic profiling to discriminate wheat near isogenic lines, with quantitative trait loci at chromosome $2 \mathrm{DL}$, varying in resistance to Fusarium head blight. Can J Plant Sci. 88(4):789-797.

Hasan Y, Turner PD (1998) The comparative importance of different oil palm tissues as infection sources for basal stem rot in replantings. Planter. 74(864):119-135.

Hill CB, Roessner U (2013) Metabolic profiling of plants by GC-MS. In: Weckwerth W, Kahl G (ed) The handbook of plant metabolomics, 1st edn. Wiley-VCH Verlag GmbH \& Co., Weinheim, Germany.

Hushiarian R, Yusof NA, Dutse SW (2013) Detection and control of Ganoderma boninense:strategies and perspective. Springer Plus. 2:1-12.

Ibrahim AD, Abubakar A, Aliero AA, Sani A, Yakubu SE (2011) Volatile metabolites profiling for discriminating tomato fruits inoculated with some bacterial pathogens. J Pharm Biomed Sci. 1(5):79-84.

Idris AS (2011) Biology, detection and control of Ganoderma in oil palm. In: Basri MW, Choo YM, Chan $\mathrm{KW}$ (ed) Further advances in oil palm research (20002010), vol 1. MPOB, Malaysia.

Idris AS, Kushairi A, Ismail S, Ariffin D (2004) Selection for partial resistance in oil palm progenies to Ganoderma basal stem rot. J Oil Palm Res. 16(2):12-18.

Idris AS, Mohd Shukri I, Norman K, Choo Y-M, Kushairi A, Hanafi MM, Mohd Nawawi W, Zaafar MD (2015) Chemical fertiliser GanoCare ${ }^{\mathrm{TM}}$ as preventive treatment in controlling Ganoderma disease of oil palm. MPOB Information Series. No 564:1-4.

Jones OAH, Maguire ML, Griffin JL, Jung Y-H, Shibato J, Rakwal R, Agrawal GK, Jwa N-S (2011) Using metabolic profiling to assess plant-pathogen interactions: an example using rice (Oryza sativa) and the blast pathogen Magnaporthe grisea. Eur J Plant Pathol. 129:539-554.

Kim S-J, Jeong S-H, Hur Y-Y, Jung S-M (2015) Metabolite profiling of four different tissue locations in grape leaf of brown spot disease caused by Pseudocercospora vitis. Plant Omics. 8(6):523-528.

Ma C, Wang H, Lu X, Wang H, Xu G, Liu B (2009) Terpenoid metabolic profiling analysis of transgenic Artemisia annua L. by comprehensive two-dimensional gas chromatography time-of-flight mass spectrometry. Metabolomics. 5:497-506.

Miedes E, Vanholme R, Boerjan W, Molina A (2014) The role of the secondary cell wall in plant resistance to pathogens. Front Plant Sci. 5:1-13.

Morgenthal K, Wienkoop S, Wolschin F, Weckwerth W (2007) Integrative profiling of metabolites and proteins: Improving pattern recognition and biomarker selection for systems level approaches. In: Weckwerth, W (ed) Metabolomics:methods and protocols, Methods Mol Biol, vol. 358. Humana Press, Totowa, New York.

MPOB (2016) Overview of the Malaysian oil palm industry 2016. Economics and Industry Development Division. Ministry of Plantation Industries and Commodities. http://bepi.mpob.gov.my/images/overview/Overview_of_In dustry_2016.pdf
Musharraf SG, Siddiqui AJ, Shamsi T, Choudhary MI, Rahman A (2016) Serum metabonomics of acute leukemia using nuclear magnetic resonance spectroscopy. Sci Rep. 6:1-9.

Nurazah Z, Idris AS, Kushairi A, Ramli US (2013) Metabolite profiling of oil palm towards understanding basal stem rot (BSR) disease. J Oil Palm Res. 25(1):58-71.

Nusaibah SA, Siti Nor Akmar A, Idris AS, Sariah M, Mohamad Pauzi Z (2016) Involvement of metabolites in early defense mechanism of oil palm (Elaeis guineensis Jacq.) against Ganoderma disease. Plant Physiol Bioch.109:156-165.

Oil World Annual (2016) Global analysis of all major oilseed, oils and oil meals supply, demand and price outlook. Oil World Annual 2016, vol. 1, ISTA Mielke $\mathrm{GmbH}$, Germany

Ramírez V, Agorio A, Coego A, García-Andrade J, Hernández MJ, Balaguer B, Ouwerkerk PB, Zarra I, Vera P (2011) MYB46 modulates disease susceptibility to Botrytis cinerea in Arabidopsis. Plant Physiol. 155(4):1920-1935.

Robotti E, Manfredi M, Marengo E (2014) Biomarkers discovery through multivariate statistical methods: A review of recently developed methods and applications in proteomics. J Proteom Bioinform. S3-003:1-20.

Scandiani MM, Luque AG, Razori MV, Casalini LC, Aoki T, O’Donnell K, Cervigni GDL, Spampinato CP (2015) Metabolic profiles of soybean roots during early stages of Fusarium tucumaniae infection. J Exp Bot. 66(1):391-402.

Scheller HV, Ulvskov P (2010) Hemicelluloses. Annu Rev Plant Biol. 61:263-289.

Seger C, Sturm S (2007) Analytical aspects of plant metabolite profiling platforms: current standings and future aims. J Proteome Res. 6:480-497.

Smart CC, Flores S (1997) Overexpression of D-myoinositol-3-phospates synthase leads to elevated levels of inositol in Arabidopsis. Plant Mol Biol. 33(5):811-820.

Srivastava S, Bist V, Srivastava S, Singh PC, Trivedi PK, Asif MH, Chauhan PS, Nautiyal CS (2016) Unraveling aspect of Bacillus amyloliquefaciens mediated enhanced production of rice under biotic stress of Rhizoctonia solani. Front Plant Sci. 7:1-16.

Sun L, Yang D-L, Kong Y, Chen Y, Li X-Z, Zeng L-J, Li Q, Wang E-T, He Z-H (2014) Sugar homeostasis mediated by cell wall invertase GRAIN INCOMPLETE FILLING 1 (GIF1) plays a role in pre-existing and induced defence in rice. Mol Plant Pathol. 15(2):161-173.

Sundram K, Sambanthamurthi R, Tan Y-A (2003) Palm fruit chemistry and nutrition. Asia Pacific J Clin Nutr. 12 (3):355-362.

Susanto A, Sudharto PS, Purba RY (2005) Enhancing biological control of basal stem rot disease (Ganoderma boninense) in oil palm plantations. Mycopathologia. 159:153-157.

Suvagandha D, Nishijo M, Swaddiwudhipong W, Honda R, Ohse M, Kuhara T, Nakagawa H, RuangyuttikarnW (2014) A biomarker found in cadmium exposed residents of Thailand by metabolome analysis. Int J Environ Res Public Health. 11:3661-3677.

Syahanim S, Abrizah O, Mohamad Arif AM, Idris AS, Mohd Din A (2013) Identification of differentially expressed proteins in oil palm seedlings artificially infected with Ganoderma: A proteomics approach. J Oil Palm Res. 25(3):298-304.

Szymańska E, Saccenti E, Smilde AK, Westerhuis JA (2012) Double-check: validation of diagnostic statistics for PLSDA models in metabolomics studies. Metabolomics. 8(1):3-16. 
Triba MN, Le Moyec L, Amathieu R, Goossens C, Bouchemal N, Nahon P, Rutledge DN, Savarin P (2015) PLS/OPLS models in metabolomics: the impact of permutation of dataset rows on the K-fold cross-validation quality parameters. Mol Biosyst. 11(1):13-19.

Vorwerk S, Somerville S, Somerville C (2004) The role of plant cell wall polysaccharide composition in disease resistance. Trends Plant Sci. 9(4):203-209.

Walters D, Raynor L, Mitchell A, Walker R, Walker K (2004) Antifungal activities of four fatty acids against plant pathogenic fungi. Mycopathologia. 157:87-90.

Wang Y, Gao D, Chen Z, Li S, Gao C, Cao D, Liu F, Liu H, Jiang Y (2013) Acridone derivative 8a induces oxidative stress-mediated apoptosis in CCRF-CEM leukemia cells: Application of metabolomics in mechanistic studies of antitumor agents. PLoS One. 8(5):1-9.

Wang Y, Xu L, Shen H, Wang J, Liu W, Zhu X, Wang R, Sun X, Liu L (2015) Metabolomic analysis with GC-MS to reveal potential metabolites and biological pathways involved in $\mathrm{Pb}$ and $\mathrm{Cd}$ stress response of radish roots. Sci Rep. 5:1-13.
Wiklund S, Johansson E, Sjöström L, Mellerowicz EJ, Edlund U (2008) Visualization of GC/TOF-MS-based metabolomics data for identification of biochemically interesting compounds using OPLS class models. Anal Chem. 80:115-122.

Xu X-H, Wang C, Li S-X, Su Z-Z, Zhou H-N, Mao L-J, Feng X-X, Liu P-P, Chen X, Snyder J-H, Kubicek C-P, Zhang CL, Lin F-C (2015) Friend or foe: differential responses of rice to invasion by mutualistic or pathogenic fungi revealed by RNAseq and metabolite profiling. Sci Rep. 5:1-14. 